\title{
Post-Whelping Abdominal Distention Resulted from Ascites Caused by Perforated Uterus, Enteropathy, Macerated and Mummified Fetuses in a Dog - Case Report
}

\author{
Michelle L Tilghman, Kara E Sudberg and Mushtaq A Memon* \\ Loving Touch Animal Center, USA
}

Submission: February 27, 2019; Published: March 20, 2019

*Corresponding author: Mushtaq A Memon, Prof Emeritus, Washington State University, 2080 Pine Forest Drive NE, Atlanta, GA 30345, USA

\begin{abstract}
A one-year-old mixed breed bitch was examined 3 weeks after whelping with a history of abdominal distention that began three weeks ago. The bitch had delivered 5 stillborn pups one month ago. The abdominal distention had increased over the past few weeks. Physical examination revealed that the bitch was extremely anemic with a PCV of $8 \%$. The abdomen was markedly distended and hard. A serosanguinous discharge emanated from the vagina. Abdominal radiographs were taken. Radiographic examinations revealed the entire abdominal cavity appeared opaque and no serosal detail could be seen. There appeared to be a small bone in the abdomen. On exploratory abdominal surgery, the entire uterus was found to be brown and necrotic. A mummified fetus and punctured uterus in two locations was discovered. The uterus, ovaries, and as much necrotic omentum as possible were removed. Postpartum complications due to ascites, fetal mummification, and fetal maceration resulted in adhesions of the abdominal and pelvic organs, and metritis. Veterinarians should consider further diagnostics of the genital tract if any postpartum complications are noted.
\end{abstract}

Keywords: Post-whelping complications; fetal mummification; fetal maceration; abdominal distension; ascites

\section{Introduction}

A one-year-old $17.7 \mathrm{~kg}(39-\mathrm{lb})$ mixed breed bitch was referred to our Animal Center with a history of abdominal distention that began three weeks ago. The bitch had delivered 5 stillborn pups one month ago. The abdominal distention had increased over the past few weeks. Radiographs were taken during late pregnancy by a previous veterinarian which revealed 5 fetuses. The bitch was brought to our clinic when the post-whelping abdominal distention did not resolve, with a presumptive diagnosis of pyometra. Physical examination revealed that the bitch was quiet, alert, and responsive. Rectal temperature was $39.8^{\circ} \mathrm{C}$ $\left(103.7^{\circ} \mathrm{F}\right)$, and the femoral pulses were adequate and bilaterally synchronous. No heart murmurs or arrhythmias were evident during thoracic auscultation. Mucous membranes were pale pink to white, and tacky. The bitch was extremely anemic with a PCV of $8 \%$. Thoracic auscultation revealed no abnormal sounds in any of the lung fields. Masses, organomegaly, signs of pain, or other abnormalities were not detected during abdominal palpation. The abdomen was markedly distended (Figure 1) and hard. A serosanguinous discharge emanated from the vagina. Abdominal radiographs were taken.

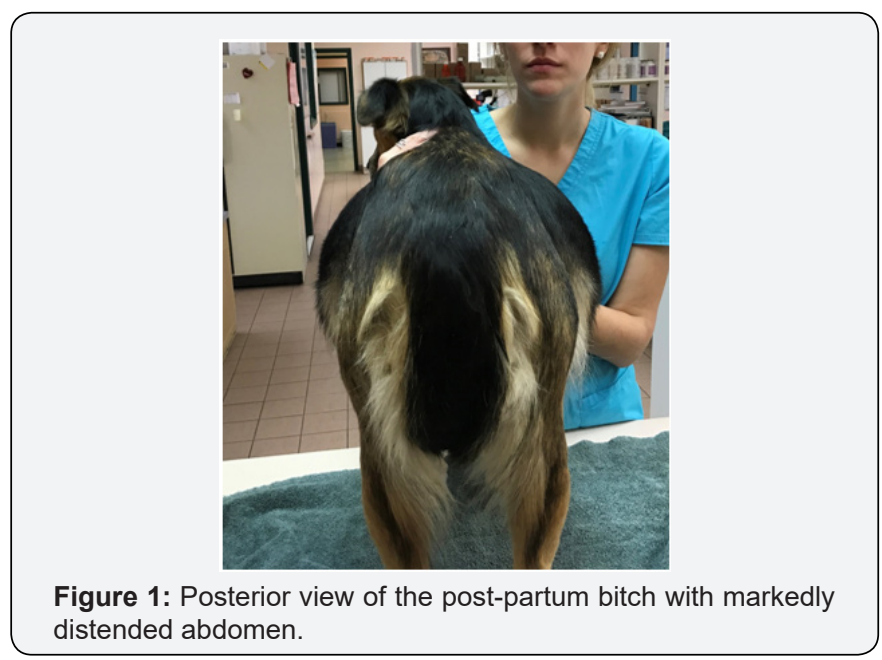




\section{Case Diagnosis}

On radiographic projections, the entire abdominal cavity appeared opaque. No serosal detail could be seen. There appeared to be a small bone in the abdomen about $5 \mathrm{~cm}$ below the 13th rib. No other abnormalities could be detected. On CBC, all parameters were within normal range except low Hemoglobin (8.1g/dl; normal 10.3-18.0), high Neutrophil (13.32K/ul; normal 3-12), and high Basophils $(0.12 \mathrm{~K} / \mathrm{ul}$, normal 0.00-0.10) count. The blood chemistry revealed high Globulin (4.7g/dl; normal 2.3-3.8), and high Alkaline Phosphatase (385U/L, normal 46-337). Other blood chemistry values were within normal range. Abdominal exploration and ovariohysterectomy were recommended, and the client agreed. Exploratory surgery and ovariohysterectomy: The bitch was anesthetized with Propofol $(10 \mathrm{mg} / \mathrm{ml}$, Zoetis), and maintained with Isoflurane throughout the procedure. Under general anesthesia, the abdomen and lower perineum were clipped and prepared for aseptic surgery. An 8-cm midline abdominal incision was made cranial to the pelvic brim. After cutting into the abdominal wall, the fluid gushed out of the abdomen resulting in relief of the abdominal distention. Attempts were made to identify the abdominal contents. On close examination, the entire uterus was found to be brown and necrotic. The omentum was necrotic as well. A mummified fetus was located in the right uterine horn close to the ovary, and apparently, the fetus had punctured the uterus in two locations on the horn (Figure 2). The uterus, ovaries, and as much necrotic omentum as possible were removed. Hair were found in the abdomen and adhered to the abdominal wall. Several small fetal ribs were located around the small intestine. Blood transfusion was performed, and the bitch received $500 \mathrm{ml}$ whole blood from a universal blood donor dog. The abdomen was lavaged with warm sterile saline, and abdominal wall was closed.

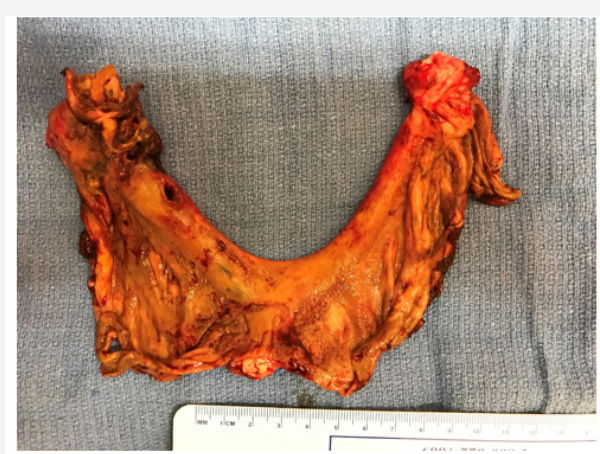

Figure 2: Reproductive tract of a postpartum bitch. Note the punctured hole in the left horn of the uterus suspected to be caused by a retained fetus.

Post-surgical follow-up: Soon after post-surgical recovery, the bitch started eating and drinking. The bitch's body weight after surgery was $10.4 \mathrm{~kg}$ (23lbs), meaning $7.3 \mathrm{~kg}$ (16lbs) of fluid was evacuated from the abdomen (Figure 3 ). The bitch was put on amoxicillin 500mg, and enrofloxacin (68mg) SID. One-week post-surgical examination revealed some abdominal distention with $2.7 \mathrm{~kg}$ (6Ib) increase in body weight, however the bitch was eating, drinking and urinating normally. The 2-week post-surgical examination showed further distension of her abdomen with $1.8 \mathrm{~kg}$ (4Ib) additional increase in her body weight. It was decided to drain extra fluid from the abdomen. After routine surgical preparation of the abdomen, $2,800 \mathrm{ml}$ fluid was drained with sterile syringe. The bitch was continued on amoxicillin and enrofloxacin as mentioned above. Due to the increasing abdominal distention and vomiting, the bitch was presented again 10 days after the last examination. On CBC, all parameters were within normal range except low hemoglobin (8.3g/dl; normal 10.3-18.0), low RBC (4.0/ul; normal 4.8-9.3), and low hematocrit (27\%, normal 36-60). The blood chemistry revealed high ALT (SGPT 386IU/L, normal 12-118), high alkaline phosphate (166IU/L, normal 5-131), and high BUN/ creatinine ratio (49, normal 4-27). Other blood chemistry values were within normal range. Based upon her inability to retain food and persistent vomiting, abdominal exploratory surgery was recommended and agreed by the owner. The bitch was anesthetized and the surgical site was prepared as discussed earlier. After cutting into the abdominal wall, a large amount of yellow purulent abdominal fluid was observed, and most of it was removed. On close examination, the entire small intestine was adhered together in a soft-ball sized ball. Small fetal size scapula, fibula and ribs were found in the abdominal cavity. The mesentery and colon were adhered to dorsal body wall. The abdominal cavity was flushed with normal saline mixed with ampicillin. Abdominal wall was closed.

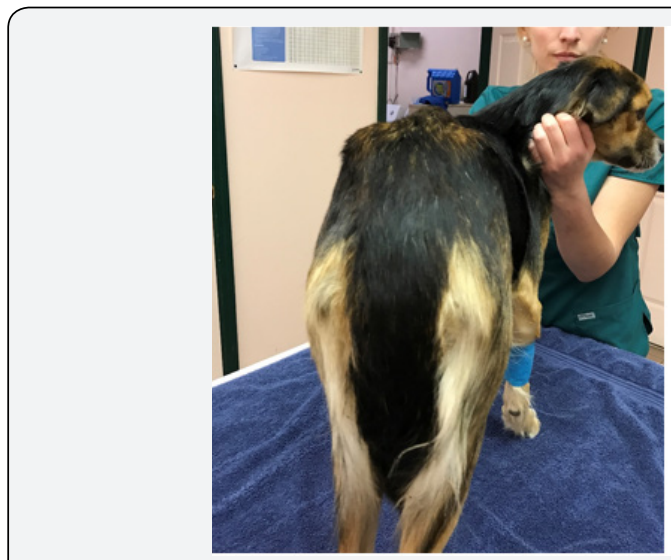

Figure 3: Post-surgical posterior view of the bitch with ascites. $7.3 \mathrm{~kg}$ of fluid was evacuated from her abdomen during the surgery.

\section{Discussion}

To authors' knowledge, the extreme post-whelping abdominal distension in a bitch with retained fetus, uterine rupture, and fetal maceration has not been reported. The uterine puncture close to the retained fetus at the tip of the left uterine horn appeared to be caused by the fetus during uterine contraction during whelping. The uterine fluid escaped through the uterine tears into the abdomen, mixed with the abdominal fluids, caused adhesions, and ultimately necrosis of the parts of omentum, and other abdominal contents. The extreme abdominal distention 
with the fluid build-up in the bitch would fit with the definition of ascites. However, the fluid build-up in the bitch's abdomen was a result of leaked uterine fluids mixed with abdominal fluids and potential bacterial infection. Even though the bitch's temperature $\left(39.8^{\circ} \mathrm{C}\right)$ was high, indicating her body's reaction to the inflammation.

Initially, pyometra was suspected, but pyometra is a progesterone-mediated uterine disease occurs during diestrus [1], not during post-whelping period due to absence of ovarian corpus luteum and progesterone production. In most of the bitches with pyometra, polyuria/or polydipsia are reported which were not reported in our case. Metritis is characterized by foul smelling red discharge from the vulva, depression, anorexia, and high temperature [1], these signs were partially reported in our case. Radiography was the diagnostic modality chosen due to cost, convenience, and urgency. It is also the most reliable method in determining location of a fetus [2]. Ascites due to organ failure was primarily ruled out with the radiographs. The heart was observed as of normal size, and no thoracic effusions were noted. This ruled out ascites due to heart failure. No uterine serosal details were obvious due to extreme abdominal distension. With the support of our radiographic findings and clinical signs, we determined an emergency surgery was necessary.

The green color vaginal discharge during whelping is considered normal lochia, whereas the mucopurulent foul-smelling discharge would be an indication of metritis [3]. The delivery of 5 stillborn pups confirmed the radiographic findings during late pregnancy. However, the discovery of the mummified and macerated fetuses confirms the presence of additional fetuses. The mummified fetus found at the tip of the uterine horn, and the puncture below in the uterus is suspicious of the fetal migration and penetrating the horn of the uterus. The findings of floating fetal ribs in the abdominal cavity confirms the maceration of an additional fetus. The presence of mummified and macerated fetuses in the uterus are probably the cause of metritis, evidenced by mucopurulent vaginal discharge in the bitch [4]. This case shows the rare condition in postpartum bitch having abdominal distention caused by ascites or excessive fluid in the abdominal cavity. Ascites as an outcome of fluid accumulation from the punctured uterus and abdominal cavity. Fetal mummification and maceration were probably the contributing factors in producing fluid, and outcome of constant irritation and probable bacterial infection.

\section{Outcome and Recommendations}

Post-partum complications due to ascites, fetal mummification, and fetal maceration resulted in adhesions of the abdominal and pelvic organs, and metritis. Two exploratory surgeries involving ovariohysterectomy, removal of mummified fetus and parts of macerated fetus provided temporary relief. Due to chronic anorexia, and debilitating condition, the bitch was euthanized. Veterinarians should consider further diagnostics of the genital tract if any post-partum complications are noted.

\section{References}

1. Johnston SD, Kustritz MVR, Olson PNS (2001) Disorders of the canine uterus and uterine tubes (oviducts). In: Johnston SD, Kustritz MVR, Olson PNS. Canine and Feline Theriogenology: WB Saunders, USA, pp. 206-224.

2. Holmes SH, Memon MA, Fite CL (2009) Dystocia and neonatal ingestion in a bitch -Theriogenology Question of the Month. J Am Vet Med Assoc 234: 205-207.

3. Memon MA, Mickelsen WD (1993) Clinical management of bitches with vaginal discharge during pregnancy. J Reprod Fert Suppl. 47: 558.

4. Serin G, Parin U (2009) Recurrent vaginal discharge causing by retained fetal bones in a bitch: a case report. Veterinarni Medicina 6: 287-290.

Your next submission with Juniper Publishers
will reach you the below assets
- Quality Editorial service
- Swift Peer Review
- Reprints availability
- E-prints Service
- Manuscript Podcast for convenient understanding
- Global attainment for your research
- Manuscript accessibility in different formats
( Pdf, E-pub, Full Text, Audio)
- Unceasing customer service
Track the below URL for one-step submission
https://juniperpublishers.com/online-submission.php

